\title{
The antioxidant effects of quercetin metabolites on the prevention of high glucose-induced apoptosis of human umbilical vein endothelial cells
}

\author{
Chia-Lun Chao ${ }^{1,2}$, Yu-Chi Hou ${ }^{3}$, Pei-Dawn Lee Chao ${ }^{3}$, Ching-Sung Weng ${ }^{4}$ and Feng-Ming $\mathrm{Ho}^{1,4 *}$ \\ ${ }^{1}$ Division of Cardiology, Department of Internal Medicine, Taoyuan General Hospital, Department of Health, The Executive Yuan, \\ Taoyuan, Taiwan \\ ${ }^{2}$ Division of Cardiology, Department of Internal Medicine, National Taiwan University College of Medicine and National Taiwan \\ University Hospital, Taipei, Taiwan \\ ${ }^{3}$ School of Pharmacy, China Medical University, Taichung, Taiwan \\ ${ }^{4}$ Department of Biomedical Engineering, Chung Yuan Christian University, Taoyuan, Taiwan
}

(Received 7 April 2008 - Revised 17 July 2008 - Accepted 25 July 2008 - First published online 14 November 2008)

Diabetes mellitus is an important risk factor for CVD. A previous study showed that high glucose induced the apoptosis of human umbilical vein endothelial cells (HUVEC) via the sequential activation of reactive oxygen species, Jun N-terminal kinase (JNK) and caspase-3. The apoptosis cascade could be blocked by ascorbic acid at the micromolar concentration $(100 \mu \mathrm{M})$. In addition to ascorbic acid, quercetin, the most abundant dietary flavonol, has been recently actively studied in vascular protection effects due to its antioxidant effect at low micromolar concentrations $(10-50 \mu \mathrm{M})$. Quercetin sulfate/glucuronide, the metabolite of quercetin in blood, however, has been rarely evaluated. In the present study, we investigated the effect of quercetin sulfate/glucuronide on the prevention of high glucose-induced apoptosis of HUVEC. HUVEC were treated with media containing high glucose $(33 \mathrm{mM})$ in the presence or absence of ascorbic acid $(100 \mu \mathrm{M})$ or quercetin sulfate/glucuronide (100 nM, $300 \mathrm{nM}$ and $1 \mu \mathrm{M}$ ). For the detection of apoptosis, a cell death detection ELISA assay was used. The level of intracellular $\mathrm{H}_{2} \mathrm{O}_{2}$ was measured by flow cytometry. JNK and caspase- 3 were evaluated by a kinase activity assay and Western blot analysis. The results showed that high glucose-induced apoptosis was inhibited by quercetin sulfate/glucuronide in a dose-dependent manner. The effect of quercetin sulfate/glucuronide on $\mathrm{H}_{2} \mathrm{O}_{2}$ quenching, inhibition of JNK and caspase-3 activity at the nanomolar concentration ( $\left.300 \mathrm{nM}\right)$ was similar to that of ascorbic acid at the micromolar concentration $(100 \mu \mathrm{M})$. The findings of the present study may shed light on the pharmacological application of quercetin in CVD.

Quercetin metabolites: Glucose: Endothelial cells: Apoptosis: Reactive oxygen species: Jun N-terminal kinase: Caspase

Diabetes mellitus is a major risk factor of cardiovascular atherosclerosis ${ }^{(1)}$. High glucose-induced endothelial cell apoptosis $^{(2-5)}$, which may disturb the integrity of the endothelial monolayer, plays a pivotal role in diabetes-associated vascular dysfunction, including atherosclerosis ${ }^{(6)}$. In cultured human umbilical vein endothelial cells (HUVEC), high glucose has been found to generate $\mathrm{H}_{2} \mathrm{O}_{2}$, which in turn activates Jun N-terminal kinase (JNK), triggers caspase- 3 and finally leads to apoptosis. The high glucose-induced $\mathrm{H}_{2} \mathrm{O}_{2}$ generation, JNK activation, triggering of caspase- 3 and facilitation of apoptosis could be suppressed by ascorbic acid $^{(2)}$. To reduce the cardiovascular events, ascorbic acid, one of the most common antioxidants, has been widely used to improve vascular function ${ }^{(7,8)}$. However, the results of clinical studies have been disappointing ${ }^{(9-11)}$. The discrepancy between the experimental and clinical studies may be because the concentrations of ascorbic acid used in experiments were much higher than those detected in humans ${ }^{(12,13)}$.

To seek other strong antioxidants, interest has grown in dietary flavonoids, which are mainly derived from vegetables and fruits. Flavonoids represent the major class of polyphenolics, and comprise several thousand plant-derived compounds with a common skeleton of phenylchromane ${ }^{(14)}$. Several epidemiological studies have shown an inverse correlation between the dietary consumption of flavonols and flavones (two main classes of flavanoids) and mortality from $\mathrm{CVD}^{(15,16)}$. Quercetin, which is well absorbed in the small intestine, and rapidly metabolised to circulating sulfates and glucuronides in plasma ${ }^{(17,18)}$, is the most abundant dietary flavonol, and recently actively studied in its vascular protection effects ${ }^{(5,19,20)}$. In the present study, we evaluated the role of quercetin metabolites (quercetin sulfate/glucuronide) on the prevention of apoptosis of HUVEC within the range of physiological concentrations ${ }^{(13,21)}$.

\section{Materials and methods}

Preparation of quercetin sulfate/glucuronide

Quercetin sulfate/glucuronide was prepared from the serum of rats that were administered with quercetin and the

Abbreviations: DCFH-DA, $2^{\prime}, 7^{\prime}$-dichlorofluorescin diacetate; EGTA, ethylene glycol tetra-acetic acid; HUVEC, human umbilical vein endothelial cells; JNK, Jun N-terminal kinase; ROS, reactive oxygen species.

* Corresponding author: Dr Feng-Ming Ho, fax +886 3 3697118, email heart@mail.tygh.gov.tw 
concentration of quercetin sulfate/glucuronide was determined by HPLC after hydrolysis with sulfatase/glucuronidase as described previously ${ }^{(22,23)}$. The serum concentration of quercetin sulfate/glucuronide was $4.7 \mu \mathrm{M}$ at the sampling time. Our quantification result indicated that the serum metabolites contained mainly sulfates and only a trace of glucuronides. There was no trace of quercetin aglycone.

\section{Cell culture and cell treatment}

HUVEC were cultured as previously described ${ }^{(2)}$. Cells were seeded at a density of $1 \times 10^{5}$ per $75 \mathrm{~cm}^{2}$ flask in medium 199 (Gibco, Grand Island, NY, USA), supplemented with $20 \mathrm{~mm}$-HEPES, endothelial cell growth substance $(100 \mu \mathrm{g} / \mathrm{ml})$ (Collaborative Research Inc., Waltham, MA, USA) and $20 \%$ fetal calf serum (Gibco). The cultures were maintained at $37^{\circ} \mathrm{C}$ with a gas mixture of $5 \% \mathrm{CO}_{2}-95 \%$ air. Subcultures were performed with trypsin-EDTA. All media were supplemented with heparin $(5 \mathrm{U} / \mathrm{ml})$, penicillin $(100 \mathrm{IU} / \mathrm{ml})$ and streptomycin $(0.1 \mathrm{mg} / \mathrm{ml})$. Medium was refreshed every third day. The endothelial cells were identified by the presence of factor VIII-related antigen (Histoset Kit; Immunolok, Carpinteria, CA, USA) and a typical 'cobblestone' appearance. Endothelial cells of the third to fifth passages in the actively growing condition were used for experiments. In experiments, HUVEC were treated with media containing $33 \mathrm{~mm}$-glucose for different time intervals (24-48 h) in the presence or absence of ascorbic acid $(100 \mu \mathrm{M})$ or quercetin sulfate/glucuronide $(100 \mathrm{nM}, 300 \mathrm{nM}$ and $1 \mu \mathrm{M})$.

\section{Detection of apoptosis}

Apoptosis of treated HUVEC was detected by the ELISA method of cell death detection (Boehringer Mannheim, Indianapolis, IN, USA) as previously described ${ }^{(2)}$. For morphological assessment, cells were collected and fixed in a methanolacetone $(1: 3, \mathrm{v} / \mathrm{v})$ solution for $5 \mathrm{~min}$ and washed with PBS. Then fixed cells were stained with Hoechst $33258(0 \cdot 1 \mathrm{ng} / \mathrm{ml})$ for $10 \mathrm{~min}$ in the dark to counterstain nuclei. Cells were observed and photographed under a Nikon fluorescence microscope.

\section{Detection of intracellular hydrogen peroxide production}

Intracellular $\mathrm{H}_{2} \mathrm{O}_{2}$ production was monitored by flow cytometry (Becton Dickinson, Franklin Lakes, NJ, USA) using $2^{\prime}, 7^{\prime}$-dichlorofluorescin diacetate (DCFH-DA; Molecular Probes, Inc., Eugene, OR, USA $)^{(2)}$. Briefly, cells $\left(2 \times 10^{5} \%\right.$ $\mathrm{ml})$ were treated with medium containing $33 \mathrm{~mm}$-glucose for the predetermined period and then co-incubated with $50 \mathrm{~mm}$ DCFH-DA. After incubation, cells were re-suspended in icecold PBS and placed on ice in the dark for flow cytometry analysis.

\section{Jun N-terminal kinase activity assay}

Cell lysis and kinase activity assays were performed as previously described ${ }^{(2)}$. Briefly, after treatment with high glucose in the presence or absence of ascorbic acid or quercetin sulfate/glucuronide, cells were washed twice with ice-cold PBS and lysed in kinase buffer containing $20 \mathrm{~mm}-\mathrm{HEPES}$ ( $\mathrm{pH} 7 \cdot 4$ ), $50 \mathrm{~mm}-\beta$-glycerophosphate, $1 \%$ Triton $\mathrm{X}-100$,
$10 \%$ glycerol, 2 mM-ethylene glycol tetra-acetic acid (EGTA), $1 \mathrm{~mm}$-dithiothreitol, $10 \mathrm{~mm}$-sodium fluoride, $1 \mathrm{~mm}$ sodium orthovanadate, aprotinin $(1 \mu \mathrm{g} / \mathrm{ml})$, leupeptin $(1 \mu \mathrm{g} /$ $\mathrm{ml}$ ) and $1 \mathrm{~mm}$-phenylmethylsulfonyl fluoride. The soluble extracts were prepared by centrifugation at $14500 \mathrm{rpm}$ for $15 \mathrm{~min}$ at $4^{\circ} \mathrm{C}$. After normalisation of protein concentration, the equal amounts of protein were incubated with protein A-sepharose and anti-JNK1 (1 $\mu$ g; C17; Santa Cruz Biotechnology, Santa Cruz, CA, USA) for $3 \mathrm{~h}$ at $4^{\circ} \mathrm{C}$. The immune complexes were washed twice with lysis buffer and then once with kinase assay buffer (20 mM-4-morpholinepropanesulfonic acid (pH 7.2), 2 mM-EGTA, $20 \mathrm{~mm}-\mathrm{MgCl}_{2}, 1 \mathrm{~mm}$-dithiothreitol and $0.1 \%$ Triton X-100). The immune complexes were then re-suspended in $20 \mathrm{ml}$ of kinase assay buffer containing $185 \mathrm{MBq}$ of $\left[\alpha-{ }^{32} \mathrm{P}\right] \mathrm{ATP}, 30 \mu \mathrm{M}$-cold ATP and $2 \mathrm{mg}$ of glutathione S-transferase-c-Jun (1/79) as a substrate for JNK1, and incubated for 20 min at $30^{\circ} \mathrm{C}$. Reaction was terminated by the addition of SDS sample buffer and boiling for $5 \mathrm{~min}$. The protein was resolved by SDS-PAGE and visualised by autoradiography.

\section{Caspase-3 activity assay}

Caspase- 3 activity was measured as described previously ${ }^{(2)}$. In brief, cells $\left(1 \times 10^{6}\right)$ were treated as indicated and the cytosolic extracts were prepared by repeated cycles of freezing and thawing in $300 \mu \mathrm{l}$ of extraction buffer (12.5 mM-2amino-2-hydroxymethyl-propane-1,3-diol (Tris) (pH 7.0), 1 mM-dithiothreitol, $0.125 \mathrm{~mm}$-EDTA, $5 \%$ glycerol, $1 \mathrm{mm-}$ phenylmethylsulfonyl fluoride, aprotinin $(1 \mu \mathrm{g} / \mathrm{ml})$ and leupeptin $(1 \mu \mathrm{g} / \mathrm{ml}))$. The cell lysates $(100 \mu \mathrm{g})$ were diluted with the buffer (50 mM-Tris (pH 7.0), 1 mM-EDTA and $10 \mathrm{mm-EGTA)}$ and incubated at $37^{\circ} \mathrm{C}$ with $10 \mathrm{~mm}$-acetyl-Asp-Glu-Val-Aspamino-4-methylcoumarin (Ac-DEVD-AMC), a caspase-3 substrate. The fluorescence of the cleaved substrate was measured by a spectrofluorometer (Hitachi F-3000; Hitachi, Tokyo, Japan) with an excitation wavelength at $380 \mathrm{~nm}$ and an emission wavelength at $460 \mathrm{~nm}$.

\section{Western blot analysis}

Protein levels of JNK1 and caspase-3 were analysed by Western blot as described previously ${ }^{(2)}$. Briefly, the cell lysates were prepared, electrotransferred and then immunoblotted with anti-JNK1 and caspase-3 polyclonal antibody (Santa Cruz Biotechnology, Santa Cruz, CA, USA). Detection was performed with Western blotting reagent ECL (Amersham, Centennial Avenue, Piscataway, NJ, USA) and chemiluminescence was exposed by the filters of Kodak X-Omat films.

\section{Statistical analysis}

Data were obtained from at least three separate experiments and presented as mean values and standard deviations. All statistical data were obtained by ANOVA followed by Student's $t$ test. $P<0.05$ was considered statistically significant.

\section{Results}

Effect of quercetin sulfate/glucuronide on high glucoseinduced apoptosis

High glucose induced apoptosis of HUVEC in a time-dependent manner that could be effectively inhibited by ascorbic acid 
$(100 \mu \mathrm{M})$ and quercetin sulfate/glucuronide (300 nM) (Fig. 1(a)). Apoptosis induced by high glucose at $48 \mathrm{~h}$ was inhibited by quercetin sulfate/glucuronide $(100 \mathrm{nM}, 300 \mathrm{nM}$ and $1 \mu \mathrm{M})$ in a dose-dependent manner. The inhibitory effect of quercetin sulfate/glucuronide $(300 \mathrm{~nm})$ on high glucose-induced apoptois was similar to that of ascorbic acid $(100 \mu \mathrm{M})$ (Fig. 1(b)).

\section{Effect of quercetin sulfate/glucuronide on high glucose-induced reactive oxygen species generation}

Flow cytometry was used to investigate the amount of $\mathrm{H}_{2} \mathrm{O}_{2}$ that was generated in high glucose-induced apoptosis of HUVEC. Treatment with high glucose was found to increase DCFH fluorescence at $48 \mathrm{~h}$, which was completely suppressed by quercetin sulfate/glucuronide at the concentration of $300 \mathrm{nM}$ (Fig. 2).

\section{Effect of quercetin sulfate/glucuronide on high glucose-elicited Jun N-terminal kinase activity}

In our previous study ${ }^{(2)}$, JNK activity in high glucose-treated HUVEC was identified to increase at $24 \mathrm{~h}$ and sustain up
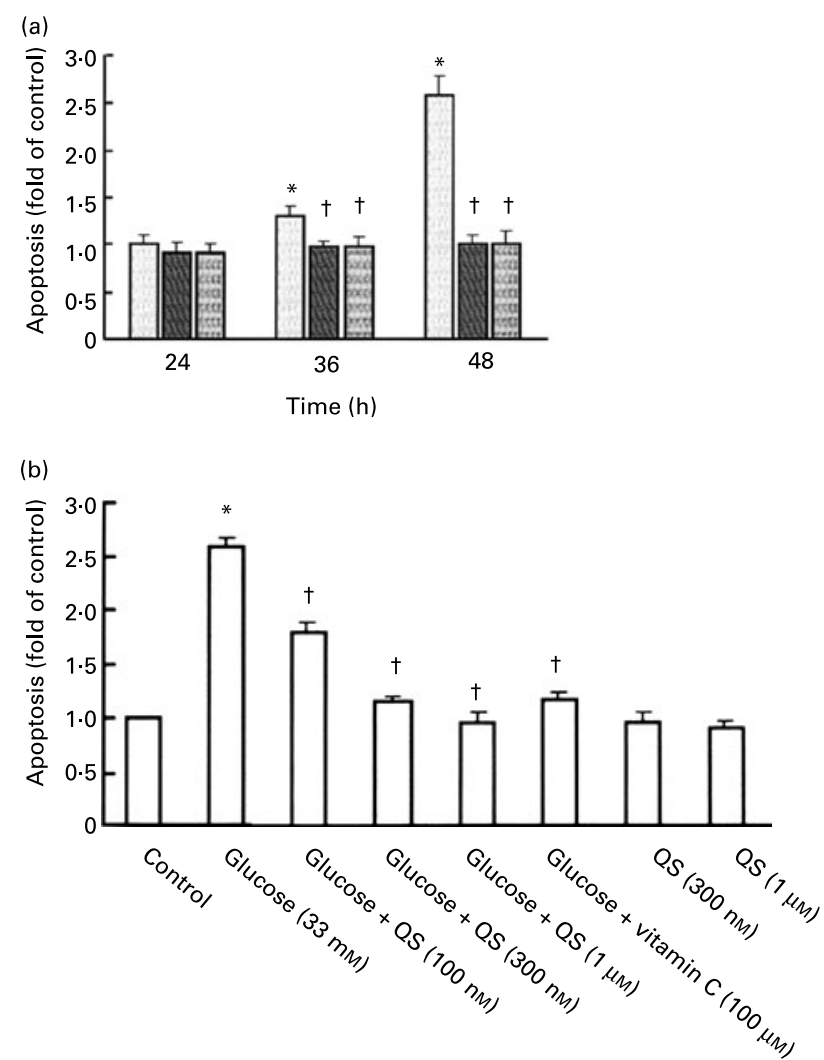

Fig. 1. (a) Time-dependent high glucose-induced apoptosis in human umbilical vein endothelial cells (HUVEC). HUVEC were treated with high glucose $(33 \mathrm{~mm} ; \square)$ for 24 to $48 \mathrm{~h}$ in the presence or absence of ascorbic acid (vitamin C; $100 \mu \mathrm{M}$; 国) or quercetin sulfate/glucuronide (QS; $300 \mathrm{~nm}$; 国). Cell death was detected by ELISA as described in the Methods. (b) Dose-dependent effect of QS on high glucose-induced apoptosis in HUVEC. HUVEC were treated with high glucose $(33 \mathrm{~mm})$ for $48 \mathrm{~h}$ in the presence or absence of vitamin C $(100 \mu \mathrm{M})$ or QS $(100 \mathrm{~nm}, 300 \mathrm{~nm}$ and $1 \mu \mathrm{M})$. The inhibitory effect of QS $(300 \mathrm{~nm})$ on apoptosis was similar to that of vitamin C $(100 \mu \mathrm{M})$. Data are means, with standard deviations represented by vertical bars. * Mean value was significantly different from that of the control group $(P<0.05)$. † Mean value was significantly different from that of the group with high glucose treatment $(P<0.05)$.

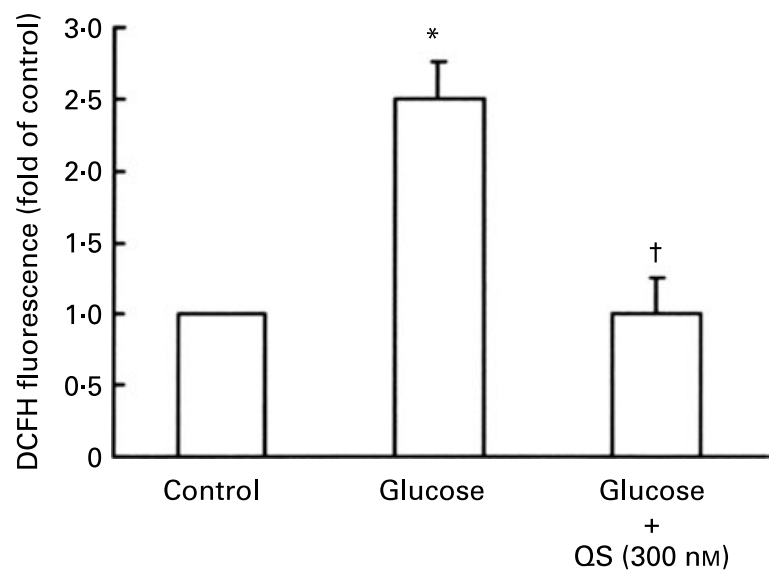

Fig. 2. High glucose-induced intracellular $\mathrm{H}_{2} \mathrm{O}_{2}$ formation in human umbilical vein endothelial cells (HUVEC). HUVEC were treated with high glucose $(33 \mathrm{~mm})$ for $48 \mathrm{~h}$ in the presence or absence of quercetin sulfate/glucuronide (QS; $300 \mathrm{~nm}$ ). Intracellular $\mathrm{H}_{2} \mathrm{O}_{2}$ production was determined by the fluorescence of $2^{\prime}, 7^{\prime}$-dichlorofluorescin diacetate (DCFH-DA) as described in the Methods. Data are means, with standard deviations represented by vertical bars. * Mean value was significantly different from that of the control group $(P<0.05)$. † Mean value was significantly different from that of the group with high glucose treatment $(P<0.05)$.

to $48 \mathrm{~h}$. In the present study, after $48 \mathrm{~h}$ treatment of high glucose in the presence of quercetin sulfate/glucuronide $(100 \mathrm{nM}$, $300 \mathrm{nM}$ and $1 \mu \mathrm{M})$, the increase of JNK activity could be reversed in a dose-dependent manner (Fig. 3 (a)). The inhibitory effect of quercetin sulfate/glucuronide $(300 \mathrm{nM})$ on JNK activity was similar to that of ascorbic acid $(100 \mu \mathrm{M})$ (Fig. 3 (b)). Quercetin sulfate/glucuronide alone did not alter JNK activity.

Effect of quercetin sulfate/glucuronide on high glucoseelicited caspase-3 activity

In our previous study ${ }^{(2)}$, caspase-3 activity, determined in high glucose-treated HUVEC, was shown to increase with time up to $48 \mathrm{~h}$ and could be inhibited by ascorbic acid $(100 \mu \mathrm{M})$. In the present study, after $48 \mathrm{~h}$ treatment of high glucose, quercetin sulfate/glucuronide ( $300 \mathrm{nM}$ and $1 \mu \mathrm{M})$ was demonstrated to suppress caspase-3 activity effectively (Fig. 4). Quercetin sulfate/glucuronide alone did not alter caspase-3 activity.

\section{Discussion}

Endothelial dysfunction is an early manifestation of vascular atherosclerosis and also an independent predictor of poor prognosis in $\mathrm{CVD}^{(6)}$. Diabetes mellitus is an important risk factor for $\mathrm{CVD}^{(1)}$. Research has revealed that high glucose would induce production of reactive oxygen species (ROS), which can cause endothelial dysfunction and even cell apoptosis $^{(2-5)}$. Our previous studies demonstrated that the high glucose-induced ROS could activate c-JUN N-terminal protein kinase (JNK), which leads to triggering of caspase-3 and facilitation of apoptosis in human endothelial cells ${ }^{(2,3)}$. Experimental studies have shown that vitamin $\mathrm{C}$ is a strong antioxidant and prevents ROS-mediated vascular dysfunction and apoptosis at high or above physiological concentrations $^{(7,8,12,13)}$. However, most of the clinical observational 


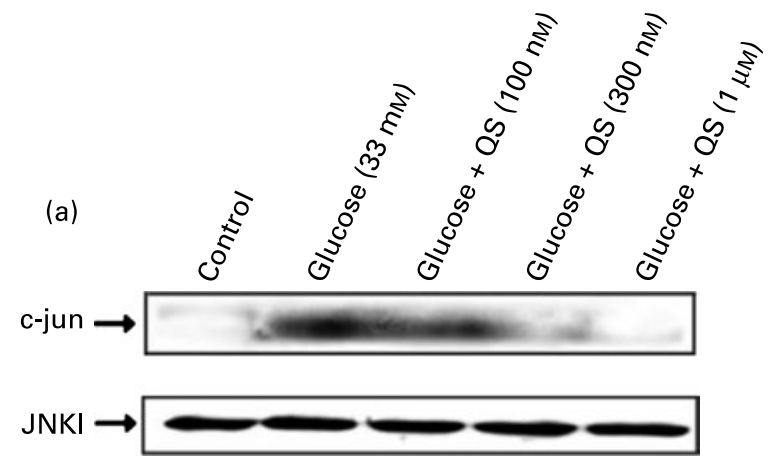

and prospective studies failed to show cardiovascular benefits from vitamin $\mathrm{C}$ therapy ${ }^{(9-11)}$. Recently, dietary flavonoids have received much attention, since epidemiological studies report an inverse association between dietary flavonoid

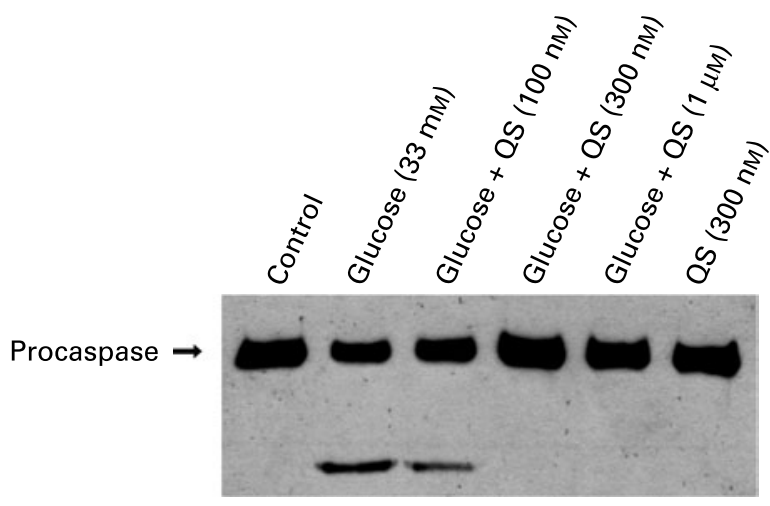

Fig. 4. Dose-dependent effect of quercetin sulfate/glucuronide (QS) on high glucose-induced caspase-3 activity. Human umbilical vein endothelial cells were treated with high glucose $(33 \mathrm{~mm})$ for $48 \mathrm{~h}$ in the presence or absence of QS (100 nM, $300 \mathrm{~nm}$ and $1 \mu \mathrm{M})$. Western blotting to identify caspase-3 was performed as described in the Methods. Caspase- 3 cleavage products were seen $48 \mathrm{~h}$ after treatment with high glucose. QS (300 nM and $1 \mu \mathrm{M})$ suppressed caspase-3 activity effectively. consumption and mortality from $\mathrm{CVD}^{(15,16)}$. Many experimental data have accumulated regarding the protective effects of flavonoids on the endothelium ${ }^{(14)}$. Quercetin $\left(3,3^{\prime}, 4^{\prime}, 5,7\right.$-pentahydroxyflavone), one of the most abundant flavonoids in the human diet, has been known as an antioxidant and represents the most prototypical example of flavonoids ${ }^{(5,19,20)}$. Quercetin is well absorbed in the small intestine and further metabolised to circulating sulfates and glucuronides ${ }^{(17,18)}$. Therefore, in view of the potential of quercetin metabolites as a pharmacological agent, it would be of interest to investigate the effect of quercetin sulfate/glucuronide within the range of physiological concentrations on ROS and the possible involvement of the signalling pathway in high glucose-induced apoptosis of human endothelial cells ${ }^{(13,21)}$.

Previous studies revealed that polyphenolic flavonoids, including quercetin, exerted protective effects in vitro against apoptosis mediated by $\mathrm{H}_{2} \mathrm{O}_{2}$ and oxidised LDL in HUVEC at the doses between $10 \mu \mathrm{M}$ and $50 \mu \mathrm{M}^{(5,20,24)}$. In the present study, we investigated the effect of quercetin sulfate/glucuronide on high glucose-induced apoptosis and found that the anti-apoptotic effect of quercetin sulfate/glucuronide was dose-dependent and remained significant at the nanomolar concentrations $(300 \mathrm{~nm}$ and $100 \mathrm{nM})$. The effective concentrations of quercetin sulfate/glucuronide used in the present experimental study were within the range of quercetin concentrations detected in humans ${ }^{(13,21)}$. The single concentration of ascorbic acid $(100 \mu \mathrm{M})$ chosen for reference in the present study was based on the experience of our previous study ${ }^{(2)}$ and the study conducted by Rössig et al. ${ }^{(7)}$, which showed that the effective concentration of ascorbic acid on inhibiting TNF- $\alpha(50 \mathrm{ng} / \mathrm{ml})$-induced apoptosis in HUVEC was $100 \mu \mathrm{M}$, but not $10 \mu \mathrm{M}$ and $50 \mu \mathrm{M}$. Nevertheless, in the present study, we did not evaluate the dose-dependent effect of ascorbic acid on apoptosis and would not attempt to jump to a conclusion that quercetin metabolites rather than vitamin $\mathrm{C}$ could have superior cardiovascular benefits in clinical studies.

High glucose may activate NADPH oxidase and lead to the production of ROS, including the superoxide anion and $\mathrm{H}_{2} \mathrm{O}_{2}^{(25,26)}$. Recently, quercetin was found to down-regulate NADPH oxidase and prevent endothelial dysfunction in spontaneously hypertensive rats ${ }^{(27)}$. Although previous studies have shown that quercetin in the low micromolar range is an effective scavenger of $\mathrm{H}_{2} \mathrm{O}_{2}^{(20,24)}$, the antioxidant effect of quercetin sulfate/glucuronide in the nanomolar range on high glucose-treated HUVEC has not yet been clarified. In the present study, we demonstrated that the low concentration of quercetin sulfate/glucuronide ( $300 \mathrm{nM})$ could also completely suppress the increase of DCFH fluorescence, which is used for detection of intracellular $\mathrm{H}_{2} \mathrm{O}_{2}$ induced by high glucose.

In the present study, quercetin sulfate/glucuronide ( $300 \mathrm{nM})$ was also found to inhibit JNK activity effectively. In different cell types, however, there were discrepant effects of quercetin on cell viability via inhibition of JNK activity. In HUVEC, quercetin showed little cytotoxicity at $100 \mu \mathrm{M}$, and inhibited JNK activity with consequent prevention of apoptosis in the low micromolar range $(10 \mu \mathrm{M} \text { to } 50 \mu \mathrm{M})^{(20)}$. In contrast, quercetin at $100 \mu \mathrm{M}$ induced apoptosis of intimal-type rat vascular smooth muscle cells via the inhibition of JNK activity ${ }^{(28)}$. It is not clear why quercetin has either an anti-apoptotic or pro-apoptotic effect on different cells. However, either antiapoptosis of HUVEC or pro-apoptosis of intimal vascular 
smooth muscle cells plays an important role in the anti-atherosclerotic effect of quercetin.

Quercetin has been demonstrated to prevent $\mathrm{H}_{2} \mathrm{O}_{2}$-mediated and LDL-induced apoptosis of HUVEC via the inhibition of caspase- 3 in the low micromolar range $(10-50 \mu \mathrm{M})^{(5,20,24)}$. In the present study, we showed that even lower doses of quercetin sulfate/glucuronide $(300 \mathrm{nM}$ and $1 \mu \mathrm{M})$ effectively suppressed caspase- 3 activity. The dose-dependent inhibitory effect of quercetin sulfate/glucuronide on $\mathrm{H}_{2} \mathrm{O}_{2}$ production, JNK and caspase- 3 activity was consistent.

Previous studies have shown that quercetin- $3^{\prime}$-sulfate and quercetin-3-glucuronide are the two major quercetin conjugates in human plasma, but the ratio of them may vary between individuals ${ }^{(18,29)}$. Other studies have also reported that quercetin- $3^{\prime}$ sulfate and quercetin-3-glucuronide can exert different or opposing effects on variant endothelial cells ${ }^{(30-32)}$. The opposing properties of the coexisting natural compounds have been postulated as the existence of the yin-yang paradigm ${ }^{(33)}$, and the balance of circulating quercetin conjugates has been suggested to determine the final effect in vivo ${ }^{(31)}$. In the present study, we were not able to indicate the substitute positions of the metabolites in the study because they were a complex mixture of sulfates and glucuronides. Our quantification result revealed that the serum metabolites contained mainly sulfates and only a trace of glucuronides. However, we also believe that the effect exerted by this metabolite combination prepared from rats mimicked the in vivo situation more than a pure compound.

In conclusion, we showed for the first time that the effect of quercetin sulfate/glucuronide on $\mathrm{H}_{2} \mathrm{O}_{2}$ quenching, inhibition of JNK and caspase-3 activity was effective at a nanomolar concentration. The findings of the present study may be useful and shed light on the pharmacological application of quercetin metabolites (quercetin sulfate/glucuronide) in CVD.

\section{Acknowledgements}

The present study was supported by grants (PTH9707 and PTH9709) from Taoyuan General Hospital, Department of Health, the Executive Yuan, Taiwan. We are grateful to Ms Chia-Chi Chen and Mr Shr-Ping Chou for their technical assistance in the present study.

The present study was supported by grants (PTH9707 and PTH9709) from Taoyuan General Hospital, Department of Health, the Executive Yuan, Taiwan. The authors C.-L. C., C.-S. W. and F.-M. H. conducted the design and implementation of the experiments, and the completion of the manuscript. Y.-C. H. and P.-D. L. C. contributed to the preparation of quercetin sulfate/glucuronide. All authors read and approved the submission of this paper. There are not any conflicts of interest in the submission of this paper.

\section{References}

1. Haffner SM, Lehto S, Ronnemaa T, Pyorala K \& Laakso M (1998) Mortality from coronary heart disease in subjects with type 2 diabetes and in nondiabetic subjects with and without prior myocardial infarction. $N$ Engl J Med 339, 229-234.

2. Ho FM, Liu SH, Liau CS, Huang PJ \& Lin-Shiau SY (2000) High glucose-induced apoptosis in human endothelial cells is mediated by sequential activations of c-Jun $\mathrm{NH}(2)$-terminal kinase and caspase-3. Circulation 101, 2618-2624.

3. Ho FM, Lin WW, Chen BC, Chao CM, Yang CR, Lin LY, Lai CC, Liu SH \& Liau CS (2006) High glucose-induced apoptosis in human vascular endothelial cells is mediated through NF- $\kappa \mathrm{B}$ and c-Jun NH2-terminal kinase pathway and prevented by PI3K/Akt/eNOS pathway. Cell Signal 18, 391-399.

4. Quagliaro L, Piconi L, Assaloni R, Martinelli L, Motz E \& Ceriello A (2003) Intermittent high glucose enhances apoptosis related to oxidative stress in human umbilical vein endothelial cells: the role of protein kinase $\mathrm{C}$ and $\mathrm{NAD}(\mathrm{P}) \mathrm{H}$-oxidase activation. Diabetes 52, 2795-2804.

5. Jeong YJ, Choi YJ, Kwon HM, Kang SW, Park HS, Lee M \& Kang YH (2005) Differential inhibition of oxidized LDL-induced apoptosis in human endothelial cells treated with different flavonoids. Br J Nutr 93, 581-591.

6. Vita JA (2005) Endothelial function and clinical outcome. Heart 91, 1278-1279.

7. Rössig L, Hoffmann J, Hugel B, Mallat Z, Haase A, Freyssinet JM, Tedgui A, Aicher A, Zeiher AM \& Dimmeler S (2001) Vitamin C inhibits endothelial cell apoptosis in congestive heart failure. Circulation 104, 2182-2187.

8. Saeed RW, Peng T \& Metz CN (2003) Ascorbic acid blocks the growth inhibitory effect of tumor necrosis factor- $\alpha$ on endothelial cells. Exp Biol Med (Maywood) 228, 855-865.

9. Knekt P, Reunanen A, Jarvinen R, Seppanen R, Heliovaara M \& Aromaa A (1994) Antioxidant vitamin intake and coronary mortality in a longitudinal population study. Am J Epidemiol 139, 1180-1189.

10. Losonczy KG, Harris TB \& Havlik RJ (1996) Vitamin E and vitamin $\mathrm{C}$ supplement use and risk of all-cause and coronary heart disease mortality in older persons: the Established Populations for Epidemiologic Studies of the Elderly. Am J Clin Nutr 64, 190-196.

11. Duvall WL (2005) Endothelial dysfunction and antioxidants. Mt Sinai J Med 72, 71-80.

12. Wynne H, Khan T, Avery P, Wood P, Ward A \& Kamali F (2006) Dietary related plasma vitamin C concentration has no effect on anticoagulation response to warfarin. Thromb Res 118, 501-504.

13. Castilla P, Echarri R, Dávalos A, Cerrato F, Ortega H, Teruel JL, Lucas MF, Gómez-Coronado D, Ortuño J \& Lasunción MA (2006) Concentrated red grape juice exerts antioxidant, hypolipidemic, and antiinflammatory effects in both hemodialysis patients and healthy subjects. Am J Clin Nutr 84, 252-262.

14. Perez-Vizcaino F, Duarte J \& Andriantsitohaina R (2006) Endothelial function and cardiovascular disease: effects of quercetin and wine polyphenols. Free Radic Res 40, 1054-1065.

15. Hertog MG, Feskens EJ, Hollman PC, Katan MB \& Kromhout D (1993) Dietary antioxidant flavonoids and risk of coronary heart disease: the Zutphen Elderly Study. Lancet 342, 1007-1011.

16. Huxley RR \& Neil HA (2003) The relation between dietary flavonol intake and coronary heart disease mortality: a metaanalysis of prospective cohort studies. Eur J Clin Nutr 57, 904-908.

17. Gee JM, DuPont MS, Day AJ, Plumb GW, Williamson G \& Johnson IT (2000) Intestinal transport of quercetin glycosides in rats involves both deglycosylation and interaction with the hexose transport pathway. J Nutr 130, 2765-2771.

18. Day AJ, Mellon F, Barron D, Sarrazin G, Morgan MR \& Williamson G (2001) Human metabolism of dietary flavonoids: identification of plasma metabolites of quercetin. Free Radic Res 35, 941-952.

19. Ishikawa Y \& Kitamura M (2000) Anti-apoptotic effect of quercetin: intervention in the JNK- and ERK-mediated apoptotic pathways. Kidney Int 58, 1078-1087. 
20. Choi YJ, Kang JS, Park JH, Lee YJ, Choi JS \& Kang YH (2003) Polyphenolic flavonoids differ in their antiapoptotic efficacy in hydrogen peroxide-treated human vascular endothelial cells. J Nutr 133, 985-991.

21. Manach C, Williamson G, Morand C, Scalbert A \& Rémésy C (2005) Bioavailability and bioefficacy of polyphenols in humans. I. Review of 97 bioavailability studies. Am J Clin Nutr 81, Suppl. 1, 230S-242S.

22. Wittig J, Herderich M, Graefe EU \& Veit M (2001) Identification of quercetin glucuronides in human plasma by high-performance liquid chromatography-tandem mass spectrometry. J Chromatogr B Biomed Sci Appl 753, 237-243.

23. Kuo HM, Ho HJ, Chao PD \& Chung JG (2002) Quercetin glucuronides inhibited 2-aminofluorene acetylation in human acute myeloid HL-60 leukemia cells. Phytomedicine 9, 625-631.

24. Choi YJ, Jeong YJ, Lee YJ, Kwon HM \& Kang YH (2005) $(-)$ Epigallocatechin gallate and quercetin enhance survival signaling in response to oxidant-induced human endothelial apoptosis. J Nutr 135, 707-713.

25. Christ M, Bauersachs J, Liebetrau C, Heck M, Gunther A \& Wehling M (2002) Glucose increases endothelial-dependent superoxide formation in coronary arteries by NAD $(\mathrm{P}) \mathrm{H}$ oxidase activation: attenuation by the 3-hydroxy-3-methylglutaryl coenzyme A reductase inhibitor atorvastatin. Diabetes 51, 2648-2652.

26. Han HJ, Lee YJ, Park SH, Lee JH \& Taub M (2005) High glucose-induced oxidative stress inhibits $\mathrm{Na}+$ /glucose cotransporter activity in renal proximal tubule cells. Am J Physiol Renal Physiol 288, F988-F996.

27. Sánchez M, Galisteo M, Vera R, Villar IC, Zarzuelo A, Tamargo J, Pérez-Vizcaíno F \& Duarte J (2006) Quercetin downregulates NADPH oxidase, increases eNOS activity and prevents endothelial dysfunction in spontaneously hypertensive rats. J Hypertens 24, 75-84.

28. Perez-Vizcaino F, Bishop-Bailley D, Lodi F, Duarte J, Cogolludo A, Moreno L, Bosca L, Mitchell JA \& Warner TD (2006) The flavonoid quercetin induces apoptosis and inhibits JNK activation in intimal vascular smooth muscle cells. Biochem Biophys Res Commun 346, 919-925.

29. de Pascual-Teresa S, Johnston KL, DuPont MS, O'Leary KA, Needs PW, Morgan LM, Clifford MN, Bao Y \& Williamson G (2004) Quercetin metabolites downregulate cyclooxygenase-2 transcription in human lymphocytes ex vivo but not in vivo. J Nutr 134, 552-557.

30. Mochizuki M, Kajiya K, Terao J, Kaji K, Kumazawa S, Nakayama T \& Shimoi K (2004) Effect of quercetin conjugates on vascular permeability and expression of adhesion molecules. BioFactors 22, 201-204.

31. Donnini S, Finetti F, Lusini L, Morbidelli L, Cheynier V, Barron D, Williamson G, Waltenberger J \& Ziche M (2006) Divergent effects of quercetin conjugates on angiogenesis. Br J Nutr 95, 1016-1023.

32. Tribolo S, Lodi F, Connor C, Suri S, Wilson VG, Taylor MA, Needs PW, Kroon PA \& Hughes DA (2008) Comparative effects of quercetin and its predominant human metabolites on adhesion molecule expression in activated human vascular endothelial cells. Atherosclerosis 197, 50-56.

33. Sengupta S, Toh SA, Sellers LA, Skepper JN, Koolwijk P, Leung HW, Yeung HW, Wong RN, Sasisekharan R \& Fan TP (2004) Modulating angiogenesis: the yin and the yang in ginseng. Circulation 110, 1219-1225. 